\title{
Towards a global list of accepted species IV: Overcoming fragmentation in the governance of taxonomic lists
}

\author{
Aaron M. Lien ${ }^{1}$ (D) - Stijn Conix ${ }^{2}$ - Frank E. Zachos ${ }^{3,4,5}$ - Les Christidis ${ }^{6}$ - Peter Paul van Dijk ${ }^{7}$. Olaf S. Bánki ${ }^{8,9}$ • \\ Saroj K. Barik ${ }^{10}$. John S. Buckeridge ${ }^{11,12}$. Mark John Costello ${ }^{13,14}$. Donald Hobern ${ }^{15}$ - Narelle Montgomery ${ }^{16,17}$. \\ Svetlana Nikolaeva ${ }^{18,19} \cdot$ Richard L. Pyle $^{20} \cdot$ Kevin Thiele $^{21}$ - Scott A. Thomson ${ }^{22}$ - Zhi-Qiang Zhang ${ }^{23,24}$. \\ Stephen T. Garnett ${ }^{25}$
}

Received: 28 January 2021 / Accepted: 9 June 2021 / Published online: 23 July 2021

(C) Gesellschaft für Biologische Systematik 2021

\begin{abstract}
Governance is the act of governing or organizing, that is a system of rules, norms, or shared strategies to guide or regulate the actions of the governed. Since the initial development of Linnaean taxonomy, a diversity of approaches have been adopted for critical taxonomic decisions, introducing pluralism to taxonomic principles and resulting in disagreements about the development of species lists. These disagreements are in part a product of the fragmented governance structure that has developed for the creation of taxonomic lists. To address these challenges and achieve the goal of a single, accepted list of life on Earth, a new governance structure for the development of taxonomic lists is needed. Here, we introduce three high-level categories of governance structure - fragmentation, monocentric governance, and polycentric governance - which differ in the way decision-making power is distributed and coordinated. We then show the problems caused by the fragmented governance structure currently in place for the development of taxonomic lists and consider the potential for a new approach grounded in either monocentric or polycentric governance. Both monocentric and polycentric approaches have the potential to address the problems inherent in the existing fragmented system. Ultimately, the best governance system for taxonomic lists will be the one that the taxonomic community is prepared to accept.
\end{abstract}

Keywords Polycentric governance $\cdot$ Monocentric governance $\cdot$ Fragmented governance $\cdot$ Knowledge commons $\cdot$ Taxonomy Taxonomic lists

\section{Introduction}

Taxonomy is a foundational scientific discipline, shaping not only the work of biologists and ecologists, but also how people see and understand the living world around us. In its most basic form, taxonomy is the science of precise categorization of the diversity of life on Earth into a rigorous system of scientific names and taxonomic concepts that allows for common understanding of the full extent and relationships of this diversity. Like many other scientific disciplines, taxonomy has evolved, developing over the centuries an agreed set of

This article is part of the Special Issue and Topical Collection Towards a global list of accepted species

Aaron M. Lien

alien@arizona.edu

Extended author information available on the last page of the article rules, norms, and shared strategies for definition, classification, and nomenclature of the life forms on Earth - what governance scholars would refer to as the "institution of taxonomy." There are long-established and widely accepted governance systems in place for some aspects of taxonomy, for example, the International Code of Zoological Nomenclature, which establishes rules for the establishment and use of scientific names for organisms known as "animals," and the International Code of Nomenclature for Algae, Fungi, and Plants, which does the same for algae, fungi, and plants. Other aspects of taxonomy, including the development and aggregation of species lists, currently lack similar governance institutions (Garnett \& Christidis, 2017).

Since the initial development of Linnaean taxonomy, a diversity of approaches have been adopted for critical taxonomic decisions about synonymy and classification, introducing pluralism to taxonomic principles at different levels and resulting in disagreements about species hypotheses and 
development of species lists (Senn et al., 2014; Costello et al., 2013a, b; Taylor et al., 2017; Thomson et al., 2018; Raposo et al., 2017). While the basic principles of Linnaean taxonomy - including that species are the fundamental units of taxonomy, binomial names of species, the international codes for naming of species - have wide agreement and adherence, there is variation in implementation of the process of taxonomy, such as from application of different species concepts that result in differences in hypothesized species boundaries and potentially overlapping or conflicting species definitions (Conix, 2018; McClure et al., 2020; Zachos, 2016). When developing species lists, these differences can result in inconsistencies from one list to another depending on the preferences of the list developer. For users of species lists, these differences can cause confusion and uncertainty, with potential effects on issues ranging from conservation to medicine (Thomson et al., 2021). Recent debates within the discipline have pointed to the potential benefits of a unified governance system for the development of taxonomic lists across all taxonomic communities leading to a single, accepted list of all life on Earth (Garnett et al., 2020; Garnett \& Christidis, 2017). Here, we assess the applicability of various governance approaches and structures, examine the current state of governance of taxonomic lists and the challenges posed by this approach, and make recommendations for development of a governance system consistent with the principles for governance of taxonomic lists as proposed by the International Union of Biological Sciences (IUBS) Working Group on the Governance of Taxonomic Lists (Garnett et al., 2020).

\section{The origins of the governance problem for taxonomy}

Governance has many definitions but is generally understood as the act of governing or organizing that is a system of rules, norms, or shared strategies to guide or regulate the actions of the governed (Robichau, 2011). In governance terms, taxonomic lists are an economic good produced by scientists (Bedford, 2014), e.g., a service that provides a benefit to society, in this case organized knowledge about the classification of organisms on Earth. Governance regimes regulate the production and supply of economic goods. There are generally four types of economic goods: public goods, private goods, club goods, and common pool goods (Ostrom \& Ostrom, 1977). These goods are defined by two basic characteristics: rivalry and excludability (Table 1). The type of economic good regulated is a consideration in selection of a governance system, as some governance systems may be better suited to management of certain types of goods.

Taxonomic information and the aggregation of this information to create taxonomic lists, as forms of scientific knowledge, are public goods (Bedford, 2014). This collective knowledge and hypotheses about the patterns and variation
Table 1 Types of economic goods as defined on the basis of excludability (is it possible for a user of a good to prevent the use of a good by others?) and rivalry (does the use of a good by one user diminish its availability for use by others?). Modified from Ostrom \& Ostrom, 1977 and Ostrom, 2005

\begin{tabular}{lll}
\hline & Excludable & Non-excludable \\
\hline Rival & Private goods & Common goods/resources \\
Non-rival & Club goods & Public goods \\
\hline
\end{tabular}

of life on Earth are non-rivalrous and non-excludable - all people have access to the taxonomic information and its use by one person does not diminish its availability to others (Frischmann et al., 2014a). Taxonomic lists, on the other hand, while also public goods, have characteristics that differentiate them from the taxonomic information used in their development. Although these lists are also non-rivalrous and non-excludable, the development of more than one list with the same taxonomic scope diminishes the value of each overlapping list by introducing inconsistency, confusion, and complexity for users of taxonomic information. For example, two competing lists, one developed by a "splitter" and the other by a "lumper," contain different, mutually exclusive information. Users of taxonomic lists, who may not be experts, must nonetheless select one approach and over the other. As such, under the current governance system for taxonomic lists, which allows for unlimited, uncoordinated production of taxonomic lists with no generally accepted mechanisms available for coordinating aggregation of lists or reconciling conflicts, the public good of taxonomic lists is subject to over-provision through the development of competing lists (Thomson et al., 2021). Scientific knowledge is not diminished by competing lists but the utility of lists to users is reduced. The whole is less than the difference of its parts.

The governance principles for taxonomic lists developed by the IUBS Working Group on the Governance of Taxonomic Lists (Table 2; Garnett et al., 2020) make exactly this distinction. In establishing principles for academic freedom (principle 5) and science as the basis for taxonomic decision-making (principle 1), the principles distinguish between the process of generation of scientific knowledge about taxonomy of species - a public good not subject to over-provision - as a matter separate from the generation of species lists - a public good that is subject to over-provision, particularly for high profile groups like vertebrates and plants. Thus, the scientific knowledge underpinning taxonomic lists is a public good that is unconstrained by taxonomic list governance and contributes to humans' overall, collective knowledge of the natural world. However, governance of taxonomic lists themselves is set apart from the process of developing taxonomic information and acknowledges the competitive nature of overlapping lists (McClure et al., 2020). Indeed, the challenge of developing a governance system that can 
Table 2 Principles for the development of taxonomic list governance developed by the IUBS Working Group on the Governance of Taxonomic Lists (Garnett et al., 2020)

1. The species list must be based on science and free from nontaxonomic considerations and interference.

2. Governance of the species list must aim for community support and use.

3. All decisions about list composition must be transparent.

4. The governance of validated lists of species is separate from the governance of the naming of species.

5. Governance of lists of accepted species must not constrain academic freedom.

6. The set of criteria considered sufficient to recognize species boundaries may appropriately vary between different taxonomic groups but should be consistent when possible.

7. A global list must balance conflicting needs for currency and stability by having archived versions.

8. Contributors need appropriate recognition.

9. List content should be traceable.

10. A global listing process needs both to encompass global diversity and to accommodate local knowledge of that diversity.

overcome the collective action failures that result in competing taxonomic lists is the primary motivation underlying the efforts of the IUBS Working Group.

Taxonomic information and lists are produced in the context of a knowledge commons. A knowledge commons is a governance venue for collective action to produce and share different types of knowledge (Frischmann et al., 2014a). A key feature of knowledge commons that must be addressed in the development and implementation of governance systems is that they involve the production of new knowledge, in this case the aggregation of taxonomic information into species lists, and the use and management of that data to ensure lists provide accurate and useful information to users (Frischmann et al., 2014b). Taxonomic lists are produced by scientists who work together or build on one another's work. Optimizing the production of taxonomic lists requires a governance approach tailored to the collective action challenges presented by this unique knowledge commons - there is no one-size-fits-all approach.

While the goal of knowledge commons governance is to encourage collective action and ensure the optimal supply of goods, implementation of a governance system may result in short-term gains and losses that are greater for some actors than for others (Baldwin et al., 2018; Olson, 1965; Ostrom, 1990; Ostrom, 2005). As a result, lack of credible commitment by participants to follow rules and divergent interests or incentives for participation are frequent barriers to collective action in commons (Frischmann et al., 2014a; Ostrom, 2005; Poteete et al., 2010). These barriers are readily apparent in the current governance of taxonomic lists. Individual taxonomists have professional incentives to participate in taxonomy, but the incentives to participate in the creation of any particular list vary and are often weak. Existing list compilers have an incentive to prioritize recognition of their own lists over others because there is no universal system in place to advance a single list that adequately acknowledges the contributions of all list creators. Additional governance is needed to address the specific challenges of credible commitment and divergent interests for the creation of a single, authoritative global taxonomic list.

\section{Governance structures and approaches}

Throughout human history, societies have developed myriad governance structures to guide and regulate the actions of individuals and groups. Some governance structures are familiar and easily recognizable, and some less so. Just as taxonomy groups individual species into larger related taxa, it is possible to develop general categories of governance structures made up of more specific forms (Elazar, 1991). Here, we introduce three high-level categories of governance structure-fragmentation, monocentric governance, and polycentric governance-which differ in the way decision-making power is distributed and coordinated (Kim, 2020). Within these categories of governance, there are several common approaches or modes of governance, including (i) command and control, or hierarchies; (ii) incentive-based, primarily economic or market-based but other incentives are possible; and (iii) collaborative or network governance approaches (Kjaer, 2004). These three approaches to governance can exist within any governance structure, though some structures lend themselves more to some approaches than others (Termeer et al., 2010). Here, we briefly introduce each of these governance structures and approaches to provide a foundation for discussion of the current status of governance of taxonomic lists and (i) the compatibility of governance structures and approaches with the principles for governance of taxonomic lists as proposed by the IUBS Working Group and (ii) the ability of different governance structures and approaches to address the specific challenges of developing a single global list of species while adhering to these principles.

\section{Fragmentation}

In fragmented governance, individualized systems of governance develop for specific sectors or groups with no hierarchical structure or system of coordination between groups (Zelli \& van Asselt, 2013; Biermann et al., 2009). In taxonomy, such fragmentation exists across taxa-mammal taxonomists have their own communities and institutions separate from turtle taxonomists - and within taxa — there are multiple 
lists of accepted bird species that have been developed using different approaches and standards (McClure et al., 2020).

Command and control and collaborative approaches are generally poor fits for fragmented governance systems. Command and control is incompatible with fragmentation because there is no hierarchy or centralization in the governance system to allow for a central government or actor to assert control over individual, fragmented governance units. In fragmented governance structures, individual units are necessarily independent from one another and lack formal ties to enable command and control by an authority. Although collaborative approaches may be possible within certain segments of a fragmented governance structure where independent individual authorities are willing to work together voluntarily, such cooperation is not encouraged, nor is there a greater authority provided by any larger governance structure. Therefore, cooperation may occur only on an ephemeral basis or for strategic reasons for only as long as collaboration enables one actor or group to advance its interests relative to another. To the extent that a fragmented governance structure begins to develop collaborative or cooperative arrangements between actors, then the structure of governance would begin to shift towards a polycentric structural form from a fragmented form.

In the absence of coordination or a hierarchical structure between groups of taxonomists, the primary mechanism available for achieving collective action are incentive-based approaches. In science, peer review functions as a weak incentive-based approach to governance. Academic taxonomists at colleges and universities, research organizations, and natural history museums, for example, are incentivized to produce peer-reviewed publications. While this approach provides an incentive for academic taxonomists to publish new taxonomic treatments, it provides little incentive for individual taxonomists to coordinate with one another to contribute to a single shared list. In fact, peer review incentives may work against this goal. Hypothetically, scientists may maximize the publishing incentive by producing new taxonomic treatments for the sole purpose of gaining additional professional benefits. In addition, peer review by its very nature is a subjective, human process. There is no consistent set of standards for acceptance or rejection of a manuscript or taxonomic treatment that are universally applied by all reviewers, nor for dispute resolution when conflicts arise during the review process. Peer review is also not a prerequisite for establishing code-compliant scientific names of species. As a result, peer review functions more as a quality control mechanism than a governance approach. These challenges compound when compiling species lists. Peer review of the full set of assertions in a checklist for a large taxonomic group is likely unachievable (see Pyle et al., 2021 for more discussion of this problem). In its current form, this fragmented governance system and incentive-based approach does not result in consistent collective action among taxonomists, causes confusion for potential users of taxonomic information outside specific taxonomic communities, and impairs the utility of taxonomic lists for policy makers (Garnett \& Christidis, 2017).

\section{Monocentric governance}

While the term monocentric governance may conjure images of monarchy or dictatorship whereby unitary heads of government rule over their subjects, monocentric governance encompasses various hierarchical forms of government, including many modern democracies. The basic form of monocentric governance systems is a hierarchy of nested governance levels (Kim, 2020; Termeer et al., 2010). A central actor, e.g., a national government or a governing board, sits at the highest level of governance and has overall authority over lower levels. Other levels of governance fall under the central government forming a hierarchy of authority with the central government at the top. Lower levels of government may have more or less authority or independence depending on the specific form of government adopted.

Though there are a wide range of specific forms of monocentric governance, because of its generally hierarchical structure, it lends itself particularly well to command and control approaches. Under command and control approaches, a government establishes laws and rules that must be followed by the governed. The rules established by the central government may be regulatory in nature, mandating or restricting certain behaviors, or outcome-based, where the scope of desired outcomes is specified and the governed are allowed to devise the means of reaching these outcomes (Ostrom, 2005). The latter approach often combines command and control with incentive-based or collaborative approaches. By setting only high-level policy goals, the central government provides other actors within the governance hierarchy with flexibility to decide how to achieve outcomes.

Within taxonomy, the governance system associated with the establishment of scientific names within taxonomic domains is a form of monocentric governance. For example, the International Commission on Zoological Nomenclature establishes and maintains the International Code of Zoological Nomenclature for animals. The Commission is a part of the International Union of Biological Sciences and is made up of members elected from and by taxonomists. It establishes and publishes the rules for zoological nomenclature, which are universally accepted and used by the scientific community (ICZN, 2020). Similar governance regimes exist in virology and botany. 


\section{Polycentric governance}

Unlike monocentric governance, polycentric governance is not strictly hierarchical in structure - individual units of governance within a polycentric system are autonomous or semiautonomous units of authority within the same system. Polycentric governance systems may be multilevel in nature, with different overlapping units of authority at, for example, municipal and state or provincial levels of government. However, each level has the ability to establish its own approach to a given problem in a way that may overlap with, but does not necessarily restrict, action at a different level. The critical difference between polycentric governance and fragmentation is that in the former the individual units of governance must take each other into account and must have mechanisms in place to resolve conflicts between different units of governance. In fragmented governance systems, individual units have no means or incentives to take one another into account, pursue mutual gains, or resolve conflicts. The benefits of polycentric governance systems include promotion of learning between different governance units, allowance for multiple goals or approaches to management, explicit recognition and accommodation of different values, and greater adaptability and resilience as a result of overlapping governance units (Blomquist, 2009; Marshall, 2009).

The precise details of what makes a governance system polycentric versus fragmented or hierarchical can be difficult to define (Carlisle \& Gruby, 2019). Individual units within a polycentric system must have significant levels of independence from one another and actual decision-making authority. The number of governance units necessary to constitute a polycentric system and the amount of autonomy necessary to qualify as polycentric rather than hierarchical are both ambiguous (Carlisle \& Gruby, 2019). The basic mechanisms of a polycentric governance system are cooperation, coercion, and competition (Heikkila et al., 2018). It is via these mechanisms that different units of governance within the overall polycentric structure take one another into account and form a functioning governance system. In this way, polycentric governance is most compatible with collaborative and network governance approaches and least compatible with hierarchical or command and control approaches. Economic or other types of incentives can fit within a polycentric system as a means to encourage cooperation or competition.

In taxonomy, individual taxonomists who propose a species list are not governance units because they lack decisionmaking authority beyond themselves. However, at the international scale, taxonomists have developed structures that function as a polycentric system to build lists of species. Most significantly, over the last 20 to 25 years, Species 2000 has engaged with 172 experts to construct the Catalogue of Life (COL) with more than 1.8 million accepted species names (Roskov et al., 2019). COL is governed as a partnership, working to support the efforts of contributors and to raise the quality of all sections of the catalogue. Many of the contributors, such as the World Register of Marine Species (WoRMS) (http://www.marinespecies.org/) and the Integrated Taxonomic Information System (ITIS, https:// www.itis.gov/), are internationally inclusive and have clear and well-defined governance mechanisms in and of themselves (Costello, 2013a). The inclusion of contributing communities in these efforts is voluntary and advanced by the communities themselves. COL is widely used as a framework for organizing species information on the web (e.g., within the Global Biodiversity Information Facility, GBIF), and WoRMS is used for data management by dozens of scientific organizations (Costello et al., 2018).

\section{Governance options for taxonomic lists}

The remainder of this paper will consider the compatibility of governance structures and approaches to the governance of taxonomic lists.

The current governance of taxonomic lists is highly fragmented and there are no overall governance systems for the establishment of a single global list. Existing high-level users of taxonomic lists, e.g., the International Union for Conservation of Nature (IUCN) or the Convention on International Trade in Endangered Species of Wild Fauna and Flora (CITES), have no authority over producers of taxonomic information, no influence over the application or standards of the peer review process, limited influence over processes seeking to develop accepted lists, and are themselves independent units in the fragmented governance system that make independent decisions about the taxonomy they accept for their lists. Other users of taxonomic lists, such as government, conservation non-governmental organizations, and private industry, act in a similarly fragmented manner, developing their own lists using their own stable of taxonomists, even though their lists may differ from those in other, often overlapping, jurisdictions. Such organizations exert command and control over the taxonomy they adopt concerning a portion of taxa, but there is no overarching authority.

Certain segments of the taxonomic community have shown a willingness to develop voluntary collaborative arrangements within the overall fragmented governance structure of taxonomic lists, e.g., the examples of COL and WoRMS noted previously. However, there is limited systematic cooperation or collaboration across many taxa. As a result, even though coordinated internally, WoRMS, COL, and other similar efforts are essentially individual governance efforts within the larger fragmented governance system of taxonomic lists.

At a workshop in February 2020 in Darwin, Australia, the IUBS Working Group on the Governance of Taxonomic Lists met to discuss the potential structure and approach of a global 
governance system for taxonomic lists. A general schematic of the potential governance system for taxonomic lists is shown in Fig. 1. In this basic governance scheme, there are three basic entities: clusters of taxonomic specialists (e.g., communities of scientists focused on a given taxonomic group), an endorsement body that receives taxonomic lists and endorses (or rejects) their inclusion in the global list on the basis of evaluation of the process used to develop the group list (not on the basis of the specific content of the group list), and the global list itself.

In this conception of taxonomic governance, taxonomist(s) with an interest in a group of organisms work alone or together to establish their own lists using taxonomic standards of their choosing. The independence of individual taxonomists is not impeded and the process of scientific publication of taxonomic treatments continues as it does today. However, for some taxonomic specialist communities, new processes are introduced to combine individual treatments into agreedupon taxonomic lists for specific taxa. These processes also do not infringe on the scientific independence of taxonomic specialist communities producing taxonomic lists. Taxonomic decisions are vested with specialists. The endorsement body bases decisions about inclusion of species lists in the single global species list on the basis of an evaluation the process used for list development rather than of the science represented in those lists. For example, the endorsement body could check whether the list-makers used adequate conflictresolution mechanisms to address disagreements between specialists (Pyle et al., 2021). As is the nature of progress in science, the global list itself is subject to continuous revision
Fig. 1 General schematic of potential governance system for taxonomic lists

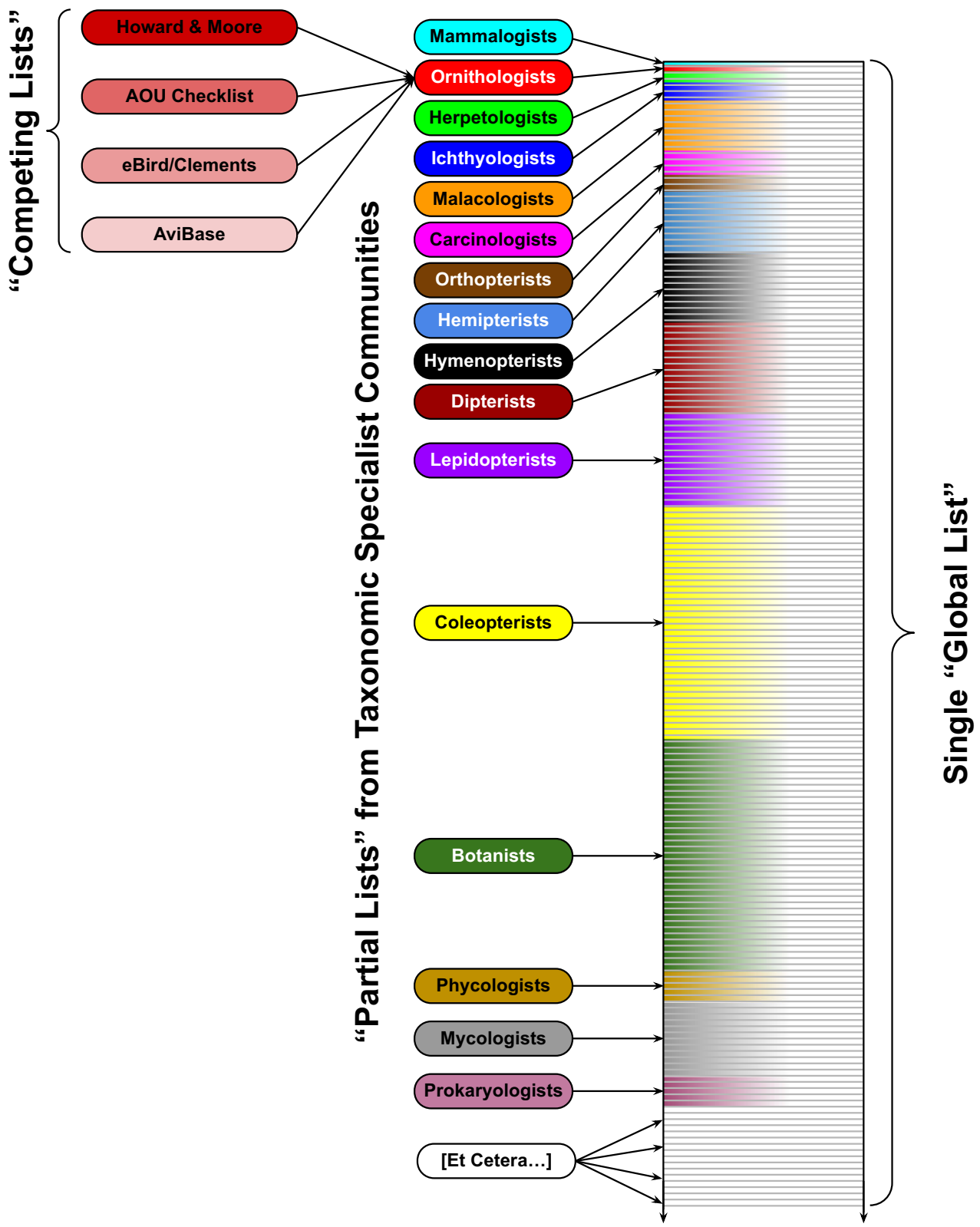


based on receipt and endorsement of new lists developed by groups that continue to meet the standards of the endorsement body.

In the proposed approach to governance of taxonomic lists presented above, the only new feature needed to transform the existing fragmented governance system into a system more capable of addressing the collective action challenge of generation of a global species list is the endorsement body. The primary role of this body in the governance system is to provide for coordination and cooperation between groups generating taxon-specific lists, thereby altering the current fragmented governance system. Both monocentric and polycentric governance approaches are fully compatible with this intended role of the endorsement body by offering opportunities for collaborative and network governance approaches that may help overcome the challenges of credible commitment and divergent interests and incentives among taxonomic communities. Indeed, monocentric and polycentric governance structures can have many similarities. Each allows for multiple units of government, each with its own specific authorities. In both monocentric and polycentric systems, governance units could have their own powers to set rules that guide the development of taxonomic lists. And in both systems, the ultimate ability of the endorsement body to advance the goal of a single, authoritative list of species on Earth would depend on its ability to gain widespread endorsement from the community of taxonomic scientists and users. But while many of the basic structural features of monocentric or polycentric governance systems are similar, the process of development and the requirements for the establishment of either structure would be quite different.

Democratic forms of monocentric governance are, at a basic level, a form of governance by mutual consent. Federalism in its various forms is one type of monocentric governance that may be well suited to the suggested governance model for taxonomic lists. Federalism is generally thought of as employing a hierarchical structure where higher levels of governance establish generally applicable laws and rules and lower levels of governance establish laws and rules more targeted to the circumstances and needs of specific segments of the governed (Elazar, 1991). In a federal system, the endorsement body would be granted its endorsement powers by the taxonomic community through mutual consent in the form of a written constitution. This constitution would define the rights and authorities of both the endorsement body and individual taxon-specific communities participating in the federal system for governance of taxonomic lists. There is no need to set out specific guidance on the governance approach within this federal system here-federalism is compatible with hierarchical, as is seen in the national government of the USA; incentivebased, as in the example of the governance system for scientific names under the auspices of the International Commission on Zoological Nomenclature; and collaborative governance, as in the more diffuse form of federalism used by Switzerland (Elazar, 1991). Decisions about what governance approaches to adopt would be up to the participants who engage in the process of developing the constitutional level rules for the federal system. The general principles for governance of taxonomic lists provided by the IUBS Working Group provide a starting point for development of a constitution with specific rights, duties, and constraints for individual bodies participating in the governance system (Garnett et al., 2020).

Ultimately, a federal approach does imply establishment of a single governance entity, the endorsement body, which is granted a minimum degree of decision-making authority over what is endorsed and included on the global list. In practice, this means that communities of scientists working with specific taxonomic groups are voluntarily ceding authority to a centralized endorsement body to make a final decision about inclusion or exclusion of taxon-specific lists in the overall endorsed global list. Although there is a great deal of variation in how taxonomists may wish to grant this authority and the extent and means by which it is exercised, ceding at least some authority is a requirement of a federal approach. For example, the endorsement body could have more or less direct decisionmaking authority about what is included in a global species list, or its powers could be limited to an arbitration role when disputes arise within taxon-specific communities developing specialist lists. Because of the nature of federalism and the need for a formal, written constitution that establishes the rules for the system, decisions about the level of authority and how it is exercised must be taken before the establishment of the endorsement body.

The need for voluntary, mutual consent puts the hard work of developing the impetus for collective action for governance of taxonomic lists before the development of a new governance system. Currently, as noted, governance of taxonomic lists is fragmented, with strong governance bodies for some taxa and weak or no governance bodies for others. A process of establishing a federal system would require participation of all of these communities, even where they currently have divergent interests, as well as a means of engaging scientists in taxa that currently have little or no formal organization. If there are not significant levels of participation across the taxonomic community in the process of developing the governance system, then the system will fail for lack of commitment from a minimum number of interested parties. Exactly what level of participation is needed to develop a credible governance system that alters rather than simply adds to the existing fragmented system is unknown. That this effort must take place before the establishment of the new governance system requires an approach to overcoming the very collective action failures that result in the current fragmented governance system-lack of credible commitment and divergent incentives. While the prospect of a mutually beneficial system may be enough to encourage participation from many groups,

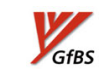


others may see little benefit of investing in development of a system with an unknown outcome.

In contrast, a polycentric governance approach would avoid the challenge of gaining endorsement for a system of governance for taxonomic lists before the creation of the governance mechanism, at least in part. A polycentric governance approach does not require the explicit agreement on constitutional rules to establish the endorsement body. In a polycentric approach, there is no requirement that the endorsement body have explicit authority over any other taxonomic body. The endorsement body is independent from other groups developing taxonomic lists for specific taxa and these groups are independent from the endorsement body. However, the goals of these bodies overlap. Individual taxonomic communities want their taxonomic lists recognized by users of taxonomy and the endorsement body wants lists of all taxa for incorporation into an authoritative global list. Because of this, taxonomists, their communities, and the endorsement body have an incentive to cooperate rather than compete so that both may achieve their overall goals: scientific advancement, community recognition, and improved outcomes for users of taxonomic lists. In a polycentric governance system, the endorsement body would seek to leverage this overlap in interests to develop de facto authority (in contrast to the de jure authority granted in a federal system via constitutional rules) to accept and endorse lists generated by taxonomic groups.

Within a polycentric system, individual units of authority use three basic mechanisms to influence one another: cooperation, competition, and coercion (Carlisle \& Gruby, 2019; Heikkila et al., 2018). Cooperation is used where two or more units in a system derive mutual benefits from working together. Competition between units for resources and other incentives can drive innovation and influence cooperation. Coercion is used between units with real or perceived power differences to influence behavior in line with the preferences of one unit over another. Many polycentric systems will also have mechanisms for conflict resolution to allow participants to address conflicts without undermining the system as a whole.

In order to establish a polycentric system successfully, it would be necessary for the IUBS Working Group and the eventual endorsement body to establish significant levels of trust with existing specialist taxonomic communities; existing developers of aggregated species lists, e.g., COL and WoRMs; and with the users of taxonomic information, e.g., CITES and the Convention on the Conservation of Migratory Species of Wild Animals (CMS). The de facto authority of the endorsement body is a product of its ability to gain the cooperation of existing taxonomic bodies to populate the global list on the one hand, and its ability to gain the cooperation of users of taxonomic data to demonstrate the utility of the global list on the other. Therefore, the need to engage the communities that develop and maintain existing taxonomic lists is not avoided in a polycentric approach. Intensive collaboration in the process of developing the endorsement mechanism is necessary to establish trust between the groups that create taxonomic lists for taxa and the endorsement body. Such a collaborative process may also enhance the likelihood of adoption of the global list by users of taxonomy because it will increase trust in the product. In addition, the need to engage users is more acute because without such cooperation, the endorsement body is unlikely to establish and maintain the incentives necessary to coerce participation in the governance system over time, or out-compete other aggregators of taxonomic lists that may have similar goals.

While the collaborative and community-building imperatives are probably just as intense for polycentric governance as for federalism, polycentric governance does not involve individual units ceding any actual authority to the endorsement body. Thus, a polycentric approach may be less threatening to established communities that generate taxonomic lists and aggregators of these lists, such as COL. Overall, a polycentric governance system is less disruptive to the current status quo, where individual groups propose taxonomic lists according to their own standards. With federalism, these groups would need to participate in the development of a set of rules for list aggregation by the endorsement body and voluntarily cede the authority to make decisions about list aggregation to this body. In a polycentric system, the endorsement body can only encourage and coerce participation in the global list by communities that generate taxon-specific lists. Individual communities are free to do as they please, including pursuing alternative approaches to list aggregation should the endorsement body not meet the needs of a given group. The governance system is more flexible; communities participating in the system for generating the global list may come and go over time as different taxonomic specialist communities and organizations form and dissolve. The authority of the endorsement body in a polycentric system would derive, not from a voluntary set of constitutional rules, but from its ability to maintain trust of both producers and users of taxonomic information over time and by increasing the use, visibility, and consistency of taxonomic information. If this trust results in widespread adoption of the endorsed global list, producers of taxonomic information will have strong incentives to adhere to the rules of the endorsement body in how they approach the development of taxon-specific lists.

\section{Conclusion}

The lack of a governance system for the development and acceptance of a single, global species list has been identified as a problem that causes conflicts between individual taxonomists and communities of taxonomists working within specific taxa and sows confusion among users of taxonomic lists 
(Garnett \& Christidis, 2017; Thompson et al., 2021). Fragmentation in governance causes these problems because there are no mechanisms in place to require one taxonomist or group of taxonomists within a taxonomic community to take one another into account when making decisions about synonymy and classification of species, e.g., decisions about species concepts and hypotheses about species boundaries. The result is the potential for multiple, scientifically sound species lists for a given taxon, forcing users of taxonomic information, who are often not taxonomists themselves, to make decisions about which species list to adopt. Examples of this problem and its consequences are offered by Garnett and Christidis (2017) and the other papers included in this special issue.

Fragmented governance of taxonomic lists results in collective action failures and a poorly functioning knowledge commons. Lack of coordination by actors within the system undermines the value of taxonomic lists for conservation, medicine, and other endeavors. Development of a new governance system could allow taxonomists to overcome existing collective action failures, increase the utility of taxonomic information for the users of lists, and increase the impact of taxonomy on society.

We suggested two basic models of governance to help overcome the collective action failures apparent in the fragmented structure to governance taxonomic lists, namely, monocentric governance, especially through some type of federal approach, and polycentric governance. Each of these models has precedent in taxonomy. The ICZN uses a highly collaborative federal structure to regulate scientific names of organisms. A central, elected body maintains the codes for nomenclature and administers a dispute resolution mechanism. The taxonomic community as a whole has voluntarily agreed to follow these rules and implements them in their dayto-day work. When conflicts arise, the Commission publishes opinions in its journal, the Bulletin of Zoological Nomenclature, where they can be freely accessed and debated by the taxonomic community to resolve disputes. In the area of taxonomic list making, COL is an example of a working polycentric governance structure. Here, individual taxonomic communities voluntarily participate in COL, generating taxon-specific species lists. The COL sets basic standards for inclusion of lists in its database, but the independent contributors to COL, e.g., WoRMS and ITIS, have their own independent governance structures.

Because these models of governance are already accepted by many taxonomists, the adoption of either federal or polycentric structures may provide a minimally disruptive way forward for developing a system of governance for taxonomic lists. Ultimately, the best governance system for taxonomic lists will be the one that the taxonomic community is prepared to accept. This and the other papers in this special issue take a first step in mapping out the "why" (Hobern et al., 2021; Pyle et al., 2021; Thiele et al., 2021; Thomson et al., 2021) and "how" (Conix et al., 2021) of governance of taxonomic lists. The next step is to move from concept to development of a governance system that can overcome collective action barriers in the way of creation of a well-functioning knowledge commons for taxonomic lists and continual refinement of a single, accepted global species list. Doing so will require a global, collaborative process to select a governance structure and an approach to develop a set of rules consistent with the selected approach. The IUBS Working Group on the Governance of Taxonomic Lists provides an impetus to this process. Its mandate is to begin the discussion among taxonomists and initiate a community-driven collaborative process based on a set of principles designed to protect scientific freedom while increasing the reach and influence of taxonomy in society (Garnett et al., 2020). Ultimately, the success of this effort will depend on broad acceptance among taxonomists that the benefits of collective action are great enough to justify the effort of establishing a new governance regime.

Acknowledgements This paper is one of a series published by the IUBS Working Group on the Governance of Taxonomic Lists. We are grateful for funding and support from the International Union of Biological Sciences and its Executive Officer Nathalie Fomproix, and administration of the grant by Roanne Ramsey (Charles Darwin University). Stijn Conix gratefully acknowledges funding from the Research Council Flanders (FWO Grant 3H200026).

Data availability Data sharing not applicable to this article as no datasets were generated or analyzed during the current study.

\section{References}

Baldwin, E., McCord, P., Dell'Angelo, J., \& Evans, T. (2018). Collective action in a polycentric water governance system. Environmental Policy and Governance, 28(4), 212-222. https://doi.org/10.1002/ eet.1810.

Bedford, D. A. D. (2014). Understanding and managing taxonomies as economic goods and services. Bulletin of the Association for Information Science and Technology, 40(4), 15-22. https://doi.org/ 10.1002/bult.2014.1720400410.

Biermann, F., Pattberg, P., van Asselt, H., \& Zelli, F. (2009). The fragmentation of global governance architectures: A framework for analysis. Global Environmental Politics, 9(4), 14-40. https://doi. org/10.1162/glep.2009.9.4.14.

Blomquist, W. (2009). Multi-level governance and natural resource management: The challenges of complexity, diversity, and uncertainty. In V. Beckmann \& M. Padmanabhan (Eds.), Institutions and sustainability: Political economy of agriculture and the environment Essays in honour of Konrad Hagedorn (pp. 109-126). Springer Netherlands. https://doi.org/10.1007/978-1-4020-9690-7_6.

Carlisle, K., \& Gruby, R. L. (2019). Polycentric systems of governance: A theoretical model for the commons. Policy Studies Journal, 47(4), 927-952. https://doi-org.ezproxy4.library.arizona.edu/10.1111/psj. 12212.

Conix, S. (2018). Integrative taxonomy and the operationalization of evolutionary independence. European Journal for Philosophy of 
Science, 8(3), 587-603. https://doi.org/10.1007/s13194-018-0202$\mathrm{z}$.

Conix, S., Garnett, S. T., Thiele, K. R., van Dijk, P. P., Christidis, L., Costello, M. J., Bánki, O. S., Barik, S. K., Buckerridge, J. S., Hobern, D., Lien, A. M., Montomery, N., Nikolaeva, S., Pyle, R. L., Thomson, S. A., Zhang, Z., \& Zachos, F. E. (2021). Towards a universal list of accepted species: Independence and stakeholder inclusion. Organisms, Diversity, and Evolution.

Costello, M. J., Bouchet, P., Boxshall, G., Fauchald, K., Gordon, D. P., Hoeksema, B. W., Poore, G. C. B., van Soest, R. W. M., Stöhr, S., Walter, T. C., Vanhoorne, B., Decock, W., \& Appeltans, W. (2013a). Global coordination and standardisation in marine biodiversity through the World Register of Marine Species (WoRMS) and related databases. PLoS One, 8(1), e51629. https://doi.org/10. 1371/journal.pone.0051629.

Costello, M. J., May, R. M., \& Stork, N. E. (2013b). Can we name earth's species before they go extinct? Science, 339(6118), 413-416. https://doi.org/10.1126/science.1230318.

Costello, M. J., Horton, T., \& Kroh, A. (2018). Sustainable biodiversity databasing: International, collaborative, dynamic, centralised. Trends in Ecology \& Evolution, 33(11), 803-805. https://doi.org/ 10.1016/j.tree.2018.08.006.

Elazar, D. J. (1991). Exploring federalism. The University of Alabama Press.

Frischmann, B. M., Madison, M. J., \& Strandburg, K. J. (2014a). Governing knowledge commons. In B. M. Frischmann, M. J. Madison, \& K. J. Strandburg (Eds.), Governing knowledge commons. Oxford University Press.

Frischmann, B. M., Madison, M. J., \& Strandburg, K. J. (2014b). Conclusion. In M. Frischmann, M. J. Madison, \& K. J. Strandburg (Eds.), Governing knowledge commons. Oxford University Press.

Garnett, S. T., \& Christidis, L. (2017). Taxonomy anarchy hampers conservation. Nature News, 546(7656), 25-27. https://doi.org/10.1038/ $546025 \mathrm{a}$.

Garnett, S. T., Christidis, L., Conix, S., Costello, M. J., Zachos, F. E., Bánki, O. S., Bao, Y., Barik, S. K., Buckeridge, J. S., Hobern, D., Lien, A., Montgomery, N., Nikolaeva, S., Pyle, R. L., Thomson, S. A., van Dijk, P. P., Whalen, A., Zhang, Z. Q., \& Thiele, K. R. (2020). Principles for creating a single authoritative list of the world's species. PLoS Biology, 18(7), e3000736. https://doi.org/ 10.1371/journal.pbio.3000736

Heikkila, T., Villamayor-Tomas, S., \& Garrick, D. (2018). Bringing polycentric systems into focus for environmental governance. Environmental Policy and Governance, 28(4), 207-211. https:// doi.org/10.1002/eet.1809.

Hobern, D., Barik, S. K., Christidis, L., Garnett, S. T., Kirk, P., Orrell, T. M., Pape, T., Pyle, R. L., Thiele, K. R., Zachos, F. E., \& Bánki, O. S. (2021). Towards a universal list of accepted species VI: The catalogue of life checklist. Organisms, Diversity and Evolution.

International Commission on Zoological Nomenclature. (2020). The international code of zoological nomenclature. Available at: https:// www.iczn.org/the-code/the-international-code-of-zoologicalnomenclature/. Retrieved: Dec. 15, 2020

Kim, R. E. (2020). Is global governance fragmented, polycentric, or complex? The state of the art of the network approach. International Studies Review, 22(4), 903-931. https://doi.org/10.1093/isr/viz052.

Kjaer, A. M. (2004). Governance. Cambridge University Press.

Marshall, G. R. (2009). Polycentricity, reciprocity, and farmer adoption of conservation practices under community-based governance. Ecological Economics, 68(5), 1507-1520. https://doi.org/10.1016/ j.ecolecon.2008.10.008.

McClure, C. J. W., Lepage, D., Dunn, L., Anderson, D. L., Schulwitz, S. E., Camacho, L., \& Bryce W. Robinson, et al. (2020). Towards reconciliation of the four world bird lists: Hotspots of disagreement in taxonomy of raptors. Proceedings of the Royal Society B:
Biological Sciences, 287(1929), 20200683. https://doi.org/10. 1098/rspb.2020.0683.

Olson, M. (1965). The logic of collective action: Public goods and the theory of groups. Harvard Universtiy Press.

Ostrom, E. (1990). Governing the commons. Princeton University Press.

Ostrom, E. (2005). Understanding institutional diversity. Princeton University Press.

Ostrom, V., \& Ostrom, E. (1977). Public goods and public choices.

Poteete, A. R., Janssen, M. A., Ostrom, E. (2010). Working together: Collective action, the commons, and multiple methods in practice. Princeton University Press.

Pyle, R. L., Barik, S. J., Christidis, L., Conix, S., Costello, M. J., Garnett, S. T., Lien, A. M., Orrell, T. M., Thomson, S. A., Zachos, F. E., \& Zhang, Z. (2021). Towards a universal list of accepted species V: The devil is in the detail. Organisms, Diversity and Evolution.

Raposo, M. A., Stopiglia, R., Brito, G. R. R., Bockmann, F. A., Kirwan, G. M., Gayon, J., \& Dubois, A. (2017). What really hampers taxonomy and conservation? A riposte to Garnett and Christidis (2017). Zootaxa, 4317(1), 179-184. https://doi.org/10.11646/zootaxa.4317. 1.10.

Robichau, R. W. (2011). The mosaic of governance: Creating a picture with definitions, theories, and debates. Policy Studies Journal, 39(s1), 113-131. https://doi.org/10.1111/j.1541-0072.2010.00389 8.x.

Roskov Y., Ower G., Orrell T., Nicolson D., Bailly N., Kirk P.M., Bourgoin T., DeWalt R.E., Decock W., Nieukerken E. van Zarucchi J., Penev L., eds. (2019). Species 2000 \& ITIS catalogue of life, 2019 annual checklist. Digital resource at www. catalogueoflife.org/annual-checklist/2019. Species 2000: Naturalis, Leiden, the Netherlands. ISSN 2405-884X.

Senn, H., Banfield, L., Wacher, T., Newby, J., Rabeil, T., Kaden, J., Kitchener, A. C., Abaigar, T., Silva, T. L., Maunder, M., \& Ogden, R. (2014). Splitting or lumping? A conservation dilemma exemplified by the critically endangered Dama gazelle (Nanger dama). PLoS One, 9(6), e98693. https://doi.org/10.1371/journal. pone.0098693.

Taylor, B. L., Archer, F. I., Martien, K. K., Rosel, P. E., Hancock-Hanser, B. L., Lang, A. R., Leslie, M. S., Mesnick, S. L., Morin, P. A., Pease, V. L., Perrin, W. F., Robertson, K. M., Parsons, K. M., Viricel, A., Vollmer, N. L., Cipriano, F., Reeves, R. R., Krützen, M., \& Baker, C. S. (2017). Guidelines and quantitative standards to improve consistency in cetacean subspecies and species delimitation relying on molecular genetic data. Marine Mammal Science, 33(S1), 132-155. https://doi.org/10.1111/mms.12411.

Termeer, C. J. A. M., Dewulf, A., \& van Lieshout, M. (2010). Disentangling scale approaches in governance research: Comparing monocentric, multilevel, and adaptive governance. Ecology and Society, 15(4), art29. https://doi.org/10.5751/ES03798-150429.

Thiele, K. R., Conix, S., Pyle, R. L., Barik, S. K., Christidis, L., Costello, M. J., van Dijk, P. P., Kirk, P., Lien, A. M., Thomson, S. A., Zachos, F. E., Zhang, Z., \& Garnett, S. T. (2021). Toward a global list of accepted species I: Why taxonomists sometimes disagree, and why this matters. Organisms, Diversity and Evolution.

Thomson, S. A., Pyle, R. L., Ahyong, S. T., Alonso-Zarazaga, M., Ammirati, J., Araya, J. F., Ascher, J. S., Audisio, T. L., AzevedoSantos, V. M., Bailly, N., Baker, W. J., Balke, M., Barclay, M. V. L., Barrett, R. L., Benine, R. C., Bickerstaff, J. R. M., Bouchard, P., Bour, R., Bourgoin, T., Boyko, C. B., Breure, A. S. H., Brothers, D. J., Byng, J. W., Campbell, D., Ceríaco, L. M. P., Cernák, I., Cerretti, P., Chang, C. H., Cho, S., Copus, J. M., Costello, M. J., Cseh, A., Csuzdi, C., Culham, A., D'Elía, G., d'Udekem d'Acoz, C., Daneliya, M. E., Dekker, R., Dickinson, E. C., Dickinson, T. A., van Dijk, P. P., Dijkstra, K. D. B., Dima, B., Dmitriev, D. A., Duistermaat, L., Dumbacher, J. P., Eiserhardt, W. L., Ekrem, T., Evenhuis, N. L., Faille, A., Fernández-Triana, J. L., Fiesler, E., 
Fishbein, M., Fordham, B. G., Freitas, A. V. L., Friol, N. R., Fritz, U., Frøslev, T., Funk, V. A., Gaimari, S. D., Garbino, G. S. T., Garraffoni, A. R. S., Geml, J., Gill, A. C., Gray, A., Grazziotin, F. G., Greenslade, P., Gutiérrez, E. E., Harvey, M. S., Hazevoet, C. J., He, K., He, X., Helfer, S., Helgen, K. M., van Heteren, A. H., Hita Garcia, F., Holstein, N., Horváth, M. K., Hovenkamp, P. H., Hwang, W. S., Hyvönen, J., Islam, M. B., Iverson, J. B., Ivie, M. A., Jaafar, Z., Jackson, M. D., Jayat, J. P., Johnson, N. F., Kaiser, H., Klitgård, B. B., Knapp, D. G., Kojima, J. I., Kõljalg, U., Kontschán, J., Krell, F. T., Krisai-Greilhuber, I., Kullander, S., Latella, L., Lattke, J. E., Lencioni, V., Lewis, G. P., Lhano, M. G., Lujan, N. K., Luksenburg, J. A., Mariaux, J., Marinho-Filho, J., Marshall, C. J., Mate, J. F., McDonough, M. M., Michel, E., Miranda, V. F. O., Mitroiu, M. D., Molinari, J., Monks, S., Moore, A. J., Moratelli, R., Murányi, D., Nakano, T., Nikolaeva, S., Noyes, J., Ohl, M., Oleas, N. H., Orrell, T., Páll-Gergely, B., Pape, T., Papp, V., Parenti, L. R., Patterson, D., Pavlinov, I. Y., Pine, R. H., Poczai, P., Prado, J., Prathapan, D., Rabeler, R. K., Randall, J. E., Rheindt, F. E., Rhodin, A. G. J., Rodríguez, S. M., Rogers, D. C., Roque, F. . O., Rowe, K. C., Ruedas, L. A., Salazar-Bravo, J., Salvador, R. B., Sangster, G., Sarmiento, C. E., Schigel, D. S., Schmidt, S., Schueler, F. W., Segers, H., Snow, N., Souza-Dias, P. G. B., Stals, R., Stenroos, S., Stone, R. D., Sturm, C. F., Štys, P., Teta, P., Thomas, D. C., Timm, R. M., Tindall, B. J., Todd, J. A., Triebel,
D., Valdecasas, A. G., Vizzini, A., Vorontsova, M. S., de Vos, J. M., Wagner, P., Watling, L., Weakley, A., Welter-Schultes, F., Whitmore, D., Wilding, N., Will, K., Williams, J., Wilson, K., Winston, J. E., Wüster, W., Yanega, D., Yeates, D. K., Zaher, H., Zhang, G., Zhang, Z. Q., \& Zhou, H. Z. (2018). Taxonomy based on science is necessary for global conservation. PLoS Biology, 16(3), e2005075. https://doi.org/10.1371/journal.pbio.2005075.

Thomson, S. A., Garnett, S. T., Weaver, H., Nikolaeva, S., Zachos, F. E., Pyle, R. L., van Dijk, P. P., Christidis, L., \& Costello, M. J. (2021). Towards a universal list of accepted species II: Consequences of inadequate taxonomic list governance. Organisms, Diversity and Evolution.

Zachos, F. E. (2016). Species concepts in biology: Historical development, theoretical foundations and practical relevance. Springer International Publishing.

Zelli, F., \& van Asselt, H. (2013). The institutional fragmentation of global environmental governance: Causes, consequences, and responses. Global Environmental Politics, 13(3), 1-13. https://doi. org/10.1162/GLEP_a_00180.

Publisher's note Springer Nature remains neutral with regard to jurisdictional claims in published maps and institutional affiliations.

\section{Affiliations}

\section{Aaron M. Lien ${ }^{1}$ (D) - Stijn Conix ${ }^{2} \cdot$ Frank E. Zachos $^{3,4,5} \cdot$ Les Christidis $^{6} \cdot$ Peter Paul van Dijk $^{7} \cdot$ Olaf S. Bánki $^{8,9}$ •

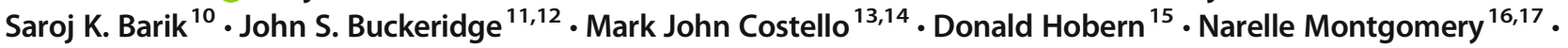 Svetlana Nikolaeva ${ }^{18,19} \cdot$ Richard L. Pyle $^{20} \cdot$ Kevin Thiele $^{21} \cdot$ Scott A. Thomson ${ }^{22} \cdot$ Zhi-Qiang Zhang $^{23,24}$. \\ Stephen T. Garnett ${ }^{25}$}

1 School of Natural Resources and the Environment, University of Arizona, Tucson, USA

2 Centre for Logic and Philosophy of Science, KU Leuven, Leuven, Belgium

3 Natural History Museum Vienna, Vienna, Austria

4 Department of Evolutionary Biology, University of Vienna, Vienna, Austria

5 Department of Genetics, University of the Free State, Bloemfontein, South Africa

6 Southern Cross University, Coffs Harbour, Australia

7 Global Wildlife Conservation, Austin, USA

8 Species 2000, Leiden, the Netherlands

9 Naturalis Biodiversity Center, Leiden, the Netherlands

10 CSIR-National Botanical Research Institute, Rana Pratap Marg, Lucknow, India

11 Earth \& Oceanic Systems Group, RMIT, Melbourne, Australia

12 Museums Victoria, Carlton, Australia

13 School of Environment, University of Auckland, Auckland, New Zealand
14 Faculty of Biosciences and Aquaculture, Nord University, Bodø, Norway

15 Species 2000, Canberra, Australia

16 Department of Agriculture, Water and the Environment, Canberra, Australia

17 Sessional Committee, Scientific Council, Convention on Migratory Species, Bonn, Germany

18 Department of Earth Sciences, The Natural History Museum, London, UK

19 Borissiak Paleontological Institute, Russian Academy of Sciences, Moscow, Russia

20 Bernice Pauahi Bishop Museum, Honolulu, USA

21 Taxonomy Australia, Australian Academy of Science, Canberra, Australia

22 Chelonian Research Institute, Oviedo, USA

23 Manaaki Whenua-Landcare Research, Auckland, New Zealand

24 School of Biological Sciences, The University of Auckland, Auckland, New Zealand

25 Research Institute for the Environment and Livelihoods, Charles Darwin University, Darwin, Australia 